\title{
Mortalidade e perfil epidemiológico dos óbitos por causas mal definidas: revisão integrativa
}

\author{
Mortality and epidemiological profile of deaths due to ill defined causes: integrative review \\ Mortalidad y perfil epidemiológico de las muertes por causas mal definidas: revisión integradora
}

Recebido: 03/02/2022 | Revisado: 16/02/2022 | Aceito: 19/02/2022 | Publicado: 28/02/2022

\author{
Hildeth Maísa Torres Farias \\ ORCID: https://orcid.org/0000-0001-7118-1855 \\ Universidade Federal dos Vales do Jequitinhonha e Mucuri, Brasil \\ E-mail: maisinhafarias@gmail.com \\ Bethânia Alves de Avelar Freitas \\ ORCID: https://orcid.org/0000-0002-3874-4799 \\ Universidade Federal dos Vales do Jequitinhonha e Mucuri, Brasil \\ E-mail: bethania.avelar@ict.ufvjm.edu.br
}

\begin{abstract}
Resumo
As causas de morte se configuram como uma das principais fontes para se conhecer o estado da saúde de populações e um percentual considerável de mortes classificadas como mal definidas comprometem a qualidade dos dados. Assim, objetivou-se realizar uma revisão integrativa sobre os estudos publicados a respeito da mortalidade e perfil epidemiológico dos óbitos por causas mal definidas. Trata-se de um estudo de revisão de literatura. As bases de dados consultadas foram PubMed, Scielo e Lilacs e os termos utilizados foram: Mortality OR Cause of death AND illdefined, em maio de 2021. Os critérios de elegibilidade para seleção foram ser artigo original; ser publicado em português, inglês ou espanhol; ser um estudo ecológico ou transversal; ser a variável de desfecho o indicador de mortalidade proporcional por causas mal definidas ou o perfil epidemiológico dos óbitos por causas mal definidas. A estratégia de busca identificou um total de 1.327 publicações. Após remoção das duplicidades e aplicação dos critérios de elegibilidade foram incluídos na revisão 22 artigos. Os artigos foram publicados entre os anos de 2007 a 2020 . Os dados coletados variam de 1979 a 2018, principalmente com as principais taxas de mortalidade por causas mal definidas nacionais, subnacionais, por estados ou capitais. Os estudos apontam que o percentual aumenta com a idade e a mortalidade proporcional por causas mal definidas reduziu ao longo do tempo no Brasil, porém existem disparidades entre regiões. Além de uma necessidade de estudo em unidades geográficas menores como microrregiões de saúde e municípios.
\end{abstract}

Palavras-chave: Mortalidade; Causas de morte; Sistemas de Informação.

\begin{abstract}
The causes of death are configured as one of the main sources to know the health status of populations and a considerable percentage of deaths classified as ill-defined compromise the quality of the data. Thus, the objective was to carry out an integrative review of published studies on mortality and the epidemiological profile of deaths from illdefined causes. This is a literature review study. The databases consulted were PubMed, Scielo and Lilacs and the terms used were: Mortality OR Cause of death AND ill-defined, in May 2021. The eligibility criteria for selection were to be an original article; be published in Portuguese, English or Spanish; be an ecological or cross-sectional study; whether the outcome variable is the indicator of proportional mortality from ill-defined causes or the epidemiological profile of deaths from ill-defined causes. The search strategy identified a total of 1,327 publications. After removing duplicates and applying the eligibility criteria, 22 articles were included in the review. The articles were published between the years 2007 to 2020 . The data collected varies from 1979 to 2018, mainly with the main rates of mortality from ill-defined causes nationally, subnationally, by states or capitals. Studies show that the percentage increases with age and proportional mortality from ill-defined causes has reduced over time in Brazil, but there are disparities between regions. In addition to a need to study in smaller geographic units such as health microregions and municipalities.
\end{abstract}

Keywords: Mortality; Causes of death; Information systems.

\section{Resumen}

Las causas de muerte se configuran como una de las principales fuentes para conocer el estado de salud de las poblaciones y un porcentaje considerable de muertes clasificadas como mal definidas comprometen la calidad de los datos. Así, el objetivo fue realizar una revisión integradora de los estudios publicados sobre la mortalidad y el perfil epidemiológico de las defunciones por causas mal definidas. Este es un estudio de revisión de la literatura. Las bases 
de datos consultadas fueron PubMed, Scielo y Lilacs y los términos utilizados fueron: Mortalidad O Causa de muerte Y mal definido, en mayo de 2021. Los criterios de elegibilidad para la selección debían ser artículo original; publicarse en portugués, inglés o español; ser un estudio ecológico o transversal; si la variable de resultado es el indicador de mortalidad proporcional por causas mal definidas o el perfil epidemiológico de las muertes por causas mal definidas. La estrategia de búsqueda identificó un total de 1327 publicaciones. Después de eliminar los duplicados y aplicar los criterios de elegibilidad, se incluyeron 22 artículos en la revisión. Los artículos fueron publicados entre los años 2007 a 2020. Los datos recolectados varían de 1979 a 2018, principalmente con las principales tasas de mortalidad por causas mal definidas a nivel nacional, subnacional, por estados o capitales. Los estudios muestran que el porcentaje aumenta con la edad y la mortalidad proporcional por causas mal definidas se ha reducido con el tiempo en Brasil, pero existen disparidades entre las regiones. Además de la necesidad de estudiar en unidades geográficas más pequeñas como microrregiones y municipios de salud.

Palabras clave: Mortalidad; Causas de muerte; Sistemas de información.

\section{Introdução}

O conhecimento da situação de saúde e o perfil epidemiológico de uma população são essenciais para a formulação de políticas de saúde. Assim sendo, observar e descrever a ocorrência de mortes e suas causas permite a visibilidade dos problemas de saúde, bem como possibilita a avaliação das políticas e dos programas, e, por conseguinte o planejamento das ações de saúde num dado território (Brasil, 2019).

A declaração de óbito é o documento padrão e oficial de coleta dos dados das pessoas falecidas no Brasil, os registros subsidiam as estatísticas vitais e epidemiológicas (Brasil, 2009). A consolidação destas informações está disponível no Sistema de Informações sobre Mortalidade (SIM) que teve sua implantação pelo Ministério da Saúde em 1976, permitindo a partir de então a comparação e análise ao longo do tempo. Vale destacar que o objetivo para a Saúde Pública da causa básica da morte é conhecê-la para deste modo prevenir a causa precipitante (Laurenti, Ruy; Jorge, 2015). Define-se assim a causa básica como a doença ou lesão que iniciou a cadeia de acontecimentos patológicos que conduziram diretamente à morte, ou as circunstâncias do acidente ou violência que produziram a lesão fatal (organização mundial de saúde, 2014). Portanto, as causas de morte se configuram como uma das principais fontes para se conhecer o estado da saúde de populações.

O óbito por causa mal definida (CMD) corresponde às situações em que a pessoa faleceu devido a uma causa que não foi possível definir. Os códigos dos óbitos por causas mal definidas segundo a Classificação Internacional de Doença $10^{\mathrm{a}}$ edição (CID-10), que entrou em vigor no país em 1996, estabelece o agrupamento do capítulo XVIII - Sintomas, sinais e achados anormais (R00-R94 e R96-R99); e dos demais capítulos (I46.9 - Parada cardíaca não especificada; I95.9 - Hipotensão não especificada; I99 - Outros transtornos do aparelho circulatório e os não especificados; J96.0 - Insuficiência respiratória aguda; J96.9 - Insuficiência respiratória não especificada; P28.5 - Insuficiência respiratória do recém-nascido) (Organização mundial de saúde, 2014).

O percentual desses óbitos no Brasil apresentou um declínio no período de 2000 a 2010, passando de 14,6\% para 8,6\%. Contudo, em 2000, os índices da Hungria, Nova Zelândia, Finlândia, Cuba e Romênia encontravam-se inferiores a 1\% (Cunha et al., 2017). Outro estudo em 2012 demonstrou porcentagens menores nos Estados Unidos (1,6\%), Canadá (1,2\%), México (1,7\%) e Chile (2,6\%), evidenciando ainda sua magnitude no Brasil (Prestes et al., 2018). A mortalidade proporcional de causas mal definidas aponta para problemas de qualidade dos dados, limitações no acesso a serviços e oferta de assistência prestada.

Entender os óbitos por causas mal definidas e o comportamento temporal torna-se fundamental devido a sua magnitude, relevância social, impacto na avaliação dos indicadores de saúde e repensar estratégias de qualidade do acesso e atenção à saúde, visto que a fidedignidade dos dados e as análises ficam comprometidas quando se tem um percentual considerável de mortes classificadas como mal definidas (Red Interagencial et al., 2009). Dessa forma, objetivou-se realizar uma revisão integrativa sobre os estudos publicados a respeito da mortalidade e perfil epidemiológico dos óbitos por causas mal definidas disponíveis na literatura científica. 


\section{Metodologia}

A revisão integrativa sobre o tema proposto cumpriu seis etapas. Na primeira etapa utilizou-se a estratégia PICOS, pois uma boa pergunta de pesquisa é formada por diversos componentes - $\mathrm{P}=$ População, $\mathrm{I}=$ Intervenção, $\mathrm{C}=$ Comparação, $\mathrm{O}$ = Desfecho, $\mathrm{S}=$ Tipo de Estudo (Galvão \& Pereira, 2014). Neste trabalho considerou-se P: óbitos não fetais por causas mal definidas, classificados no capitulo XVIII da CID-10; I: não foi contemplada; C: apenas em relação ao ano-calendário: O: variação do indicador de mortalidade proporcional por CMD e perfil epidemiológico; S: estudos ecológicos de séries temporais e transversais.

\section{Elaboração da pergunta de pesquisa}

Elaboraram-se duas perguntas norteadoras: (1) Qual a tendência temporal da mortalidade proporcional por causas mal definidas? (2) Qual o perfil epidemiológico dos óbitos por causas mal definidas?

Posteriormente, definiram-se os Descritores em Ciências da Saúde (DeCS) e os Medical Subject Headings (MeSH) que foram Causa de morte, Mortalidade e Cause of death, Mortaliy, respectivamente.

\section{Estratégia de Busca}

As bases de dados eletrônicos selecionadas foram PubMed, Scientific Electronic Library Online (Scielo) e Literatura Científica e Técnica da América Latina e Caribe (LILACS). Após definir os termos de busca no DeCS e no MeSH, foram pesquisadas as palavras-chave mais frequentes em artigos da área. Então, no dia 11/05/2021, realizou-se a busca, utilizando-se os seguintes termos: Mortality OR Cause of death AND ill-defined.

\section{Critérios de Elegibilidade}

Os estudos elegíveis deveriam apresentar os seguintes aspectos: 1) ser artigo original; 2) ser publicado em português, inglês ou espanhol; 3) ser um estudo ecológico ou transversal; 4) a variável de desfecho ser o indicador de mortalidade proporcional por causas mal definidas ou o perfil epidemiológico dos óbitos por causas mal definidas.

\section{Seleção dos Estudos}

Realizou-se a análise dos títulos e os resultados foram lançados em uma planilha de Excel para identificação das duplicidades. Posteriormente, analisaram-se os resumos para a seleção das referências a serem incluídos na fase de análise do artigo completo. Em seguida, importaram-se as publicações para o programa Mendeley para uma nova análise de duplicidade e gerenciamento das referências.

\section{Avaliação da Qualidade Metodológica}

Os artigos selecionados foram avaliados quanto à qualidade metodológica através de (I) caracterização e tamanho da população de estudo ou amostra, (II) método utilizado para avaliação do desfecho, (III) análise estatística. Também foi observada a redação dos artigos por meio da Iniciativa STROBE (Malta et al., 2010).

\section{Análise dos dados}

A análise descritiva dos artigos selecionados foi divida em duas etapas. A primeira com as informações das variáveis: Base de dados, Autor principal, Ano de publicação, Título do artigo, Idioma, País, Local de Estudo e Período avaliado (Quadro 1). Posteriormente, apresentam-se as informações: Autor principal e ano de publicação, Delineamento, Caracterização e tamanho da população de estudo ou da amostra, Método utilizado para avaliação do desfecho, Análise estatística e Principais 
resultados (Quadro 2).

\section{Resultados e Discussão}

A estratégia de busca identificou um total de 1.327 publicações nas bases de dados eletrônicos PubMed, Scielo e LILACS. Dessas, 1.126 foram excluídas após a leitura do título e 123 excluídas após análise do resumo, resultando em 78 artigos. Identificou-se ainda 37 duplicidades que foram excluídas, selecionando-se 41 artigos para leitura na íntegra. Após aplicação dos critérios de elegibilidade foram incluídos na revisão 22 artigos, sendo estes 10 estudos ecológicos, 10 transversais e 02 apresentavam os dois tipos de estudo. Os motivos de exclusão foram não avaliação dos desfechos de interesse (7) e artigos de revisão, ensaio científico, estudos: descritivo, coorte, intervenção e qualitativo (12), como podem ser observados na fFgura 1.

Figura 1 - Fluxograma do processo de seleção dos artigos incluídos na revisão integrativa.

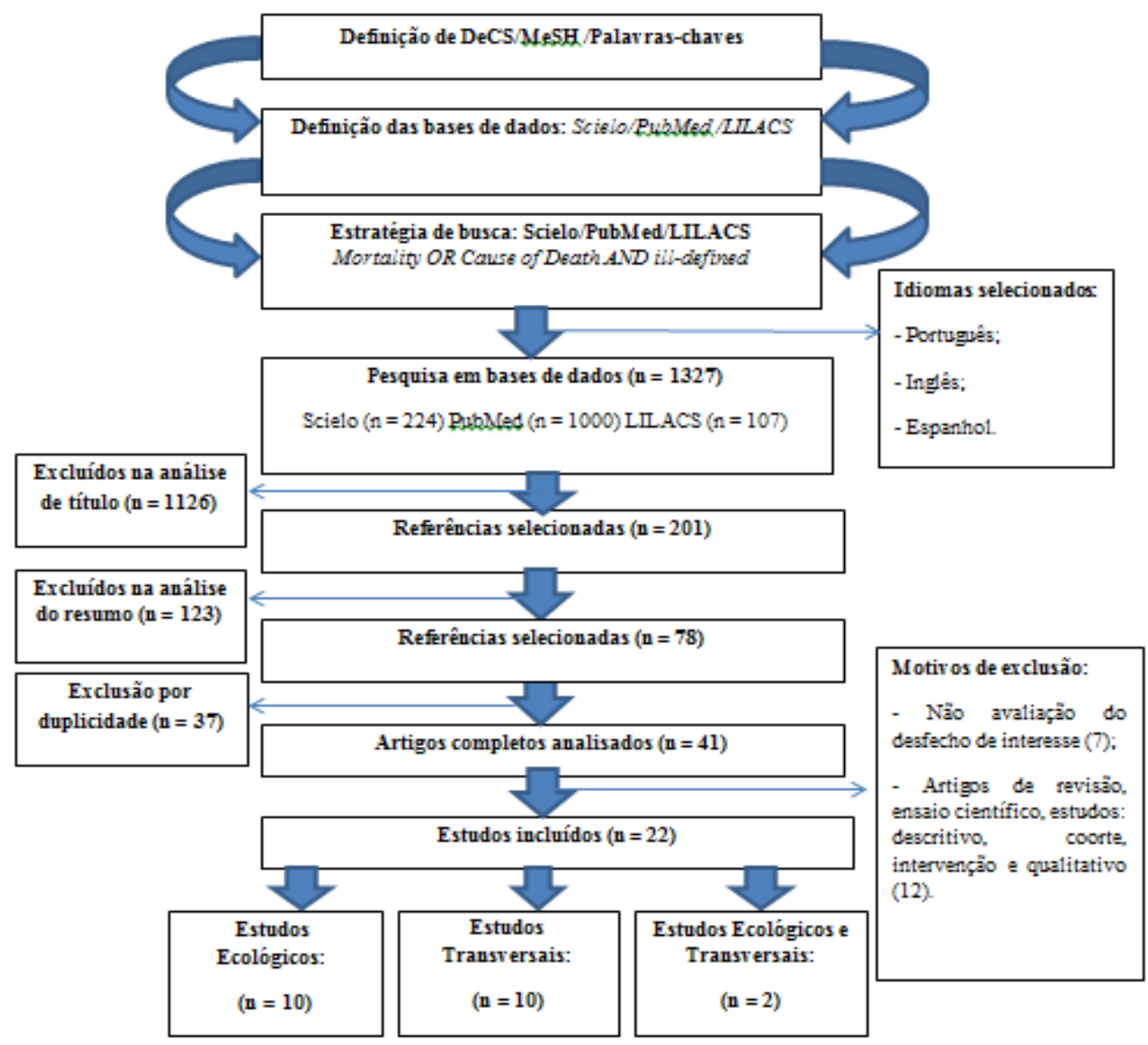

Fonte: Autores.

Os artigos foram publicados entre os anos de 2007 a 2020 e apresentaram uma ascendência ao longo do tempo e dos 22 estudos 40,9\% são recentes - dos últimos 5 anos, tendo o maior quantitativo em 2020. A relevância destes tipos de estudo é reconhecida nacional e internacionalmente (Brasil, 2019). Essas publicações são motivadas pela Agenda de Prioridades de Pesquisa do Ministério da Saúde (Brasil, 2018) e pela Agenda de Saúde Sustentável para as Américas 2018-2030 (Regional et al., 2018). Quanto ao período de coleta dos dados identificou-se que variaram de 1979 a 2018, sobretudo com as principais taxas de mortalidade por causas mal definidas nacionais, subnacionais, por estados ou capitais. Observa-se ainda que $81 \%$ dos 
estudos foram realizados no Brasil. O ano inicial dos dados coletados relaciona-se com a implantação do SIM no território brasileiro (Laurenti, Ruy; Jorge, 2015) e o último ano de coleta coincide com a disponibilização dos dados públicos no site do Departamento de Informática do Sistema Único de Saúde (DATASUS). Percebe-se assim uma lacuna no tocante aos estudos com base nas macro e microrregiões de saúde, bem como nos municípios, conforme pode se observar no Quadro 1.

Quadro 1 - Distribuição dos artigos de acordo com o autor, título, idioma, país, local do estudo e período avaliado.

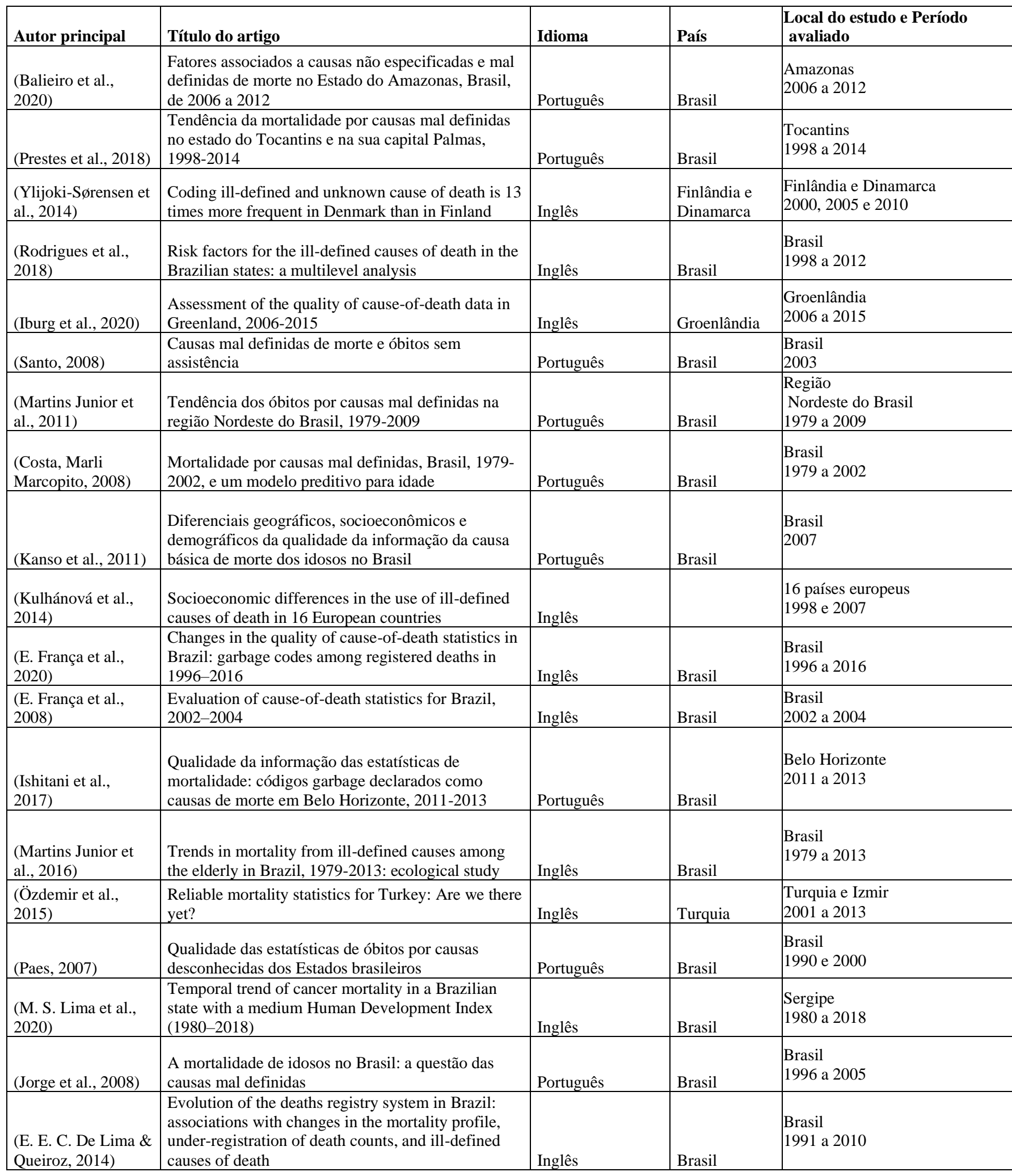




\begin{tabular}{|c|c|c|c|c|}
\hline $\begin{array}{l}\text { (E. E. C. de Lima \& } \\
\text { Queiroz, 2011) }\end{array}$ & $\begin{array}{l}\text { A evolução do sub-registro de mortes e causas de } \\
\text { óbitos mal definidas em Minas Gerais: diferenciais } \\
\text { regionais }\end{array}$ & Português & Brasil & $\begin{array}{l}\text { Minas Gerais } \\
1980 \text { a } 2007\end{array}$ \\
\hline (Abreu et al., 2010) & $\begin{array}{l}\text { A evolução da mortalidade por causas mal definidas } \\
\text { na população idosa em quatro capitais brasileiras, } \\
1996-2007\end{array}$ & Português & Brasil & $\begin{array}{l}\text { Belo Horizonte, Porto Alegre, } \\
\text { Rio de Janeiro e São Paulo } \\
1996 \text { a } 2007\end{array}$ \\
\hline $\begin{array}{l}\text { (Santos \& } \\
\text { Rodrigues, 2019) }\end{array}$ & $\begin{array}{l}\text { Análise comparativa do sistema de informação de } \\
\text { mortalidade entre municípios de uma regional de } \\
\text { saúde do estado de Pernambuco }\end{array}$ & Português & Brasil & $\begin{array}{l}\text { VI Região de Saúde de } \\
\text { Pernambuco } \\
2013\end{array}$ \\
\hline
\end{tabular}

Fonte: Autores.

As informações coletadas dos artigos selecionados quanto as características e sínteses dos estudos são apresentadas no quadro 2. Em relação ao delineamento dos estudos, observou-se que 50\% são ecológicos e 50\% transversais. Os dados foram extraídos em 95\% do Sistema de Informação sobre Mortalidade.

Quadro 2 - Características e sínteses dos estudos incluídos na revisão integrativa.

\begin{tabular}{|c|c|c|c|c|c|}
\hline $\begin{array}{l}\text { Autor principal e } \\
\text { ano de publicação }\end{array}$ & Delineamento & $\begin{array}{l}\text { Caracterização e } \\
\text { tamanho da população } \\
\text { de estudo ou amostra }\end{array}$ & $\begin{array}{l}\text { Método utilizado para } \\
\text { avaliação do desfecho }\end{array}$ & $\begin{array}{l}\text { Análise } \\
\text { estatística }\end{array}$ & Principais resultados \\
\hline (Balieiro et al., 2020) & $\begin{array}{l}\text { Estudo seccional, } \\
\text { exploratório }\end{array}$ & $\begin{array}{l}\text { Todos os óbitos não } \\
\text { fetais de residentes no } \\
\text { Amazonas, ocorridos no } \\
\text { próprio estado entre } \\
2006 \text { e } 2012 \text { e com } \\
\text { informação sobre a } \\
\text { causa básica (n= } \\
\text { 90.439). Óbitos de } \\
\text { causas inespecíficas (n= } \\
\text { 8.239) e causas mal } \\
\text { definidas (n=15.013) } \\
\text { extraídos do SIM. }\end{array}$ & $\begin{array}{l}\text { A mortalidade proporcional por } \\
\text { causas inespecíficas e mal } \\
\text { definidas, total e segundo } \\
\text { categorias das variáveis } \\
\text { explicativas selecionadas. } \\
\text { Foram selecionadas as } \\
\text { categorias da CID-10 mais } \\
\text { frequentes entre as causas } \\
\text { inespecíficas e mal definidas. } \\
\text { Foram estimadas razões de } \\
\text { chances (odds ratios - OR) de } \\
\text { mortalidade por causas } \\
\text { inespecíficas e mal definidas } \\
\text { brutas e ajustadas. }\end{array}$ & $\begin{array}{l}\text { Modelo de } \\
\text { regressão } \\
\text { logístico } \\
\text { multinominal } \\
\text { hierárquico. }\end{array}$ & $\begin{array}{l}\text { A mortalidade proporcional } \\
\text { por causas inespecíficas } \\
9,1 \% \text { e por causas mal } \\
\text { definidas } 16,6 \% \text {. A chance } \\
\text { de mortalidade por causas } \\
\text { mal definidas diminuiu ao } \\
\text { longo do período } \\
\text { analisado. A proporção de } \\
\text { morte sem assistência - } \\
\text { R98 foi } 8.584 \text { e de outras } \\
\text { causas mal definidas e as } \\
\text { não especificadas de } \\
\text { mortalidade -R99 foi } \\
4.773 \text {. A chance de causas } \\
\text { mal definidas variou } \\
\text { inversamente em relação } \\
\text { ao nível de escolaridade, a } \\
\text { partir da categoria "ensino } \\
\text { médio" até superior } \\
\text { completo". }\end{array}$ \\
\hline (Prestes et al., 2018) & $\begin{array}{l}\text { Estudo } \\
\text { epidemiológico: } \\
\text { I) estudo } \\
\text { ecológico de } \\
\text { série temporal; } \\
\text { II) estudo } \\
\text { descritivo, } \\
\text { transversal }\end{array}$ & $\begin{array}{l}\text { Todos os óbitos por } \\
\text { causas mal definidas de } \\
1998 \text { a } 2014 \text { no estado } \\
\text { do Tocantins }(n=7.464) \\
\text { e em Palmas }(n=299) \\
\text { dados extraídos do SIM. }\end{array}$ & $\begin{array}{l}\text { Tendência temporal da } \\
\text { mortalidade por causas mal } \\
\text { definidas como variável } \\
\text { dependente }(Y) \text { e o ano- } \\
\text { calendário como variável } \\
\text { independente }(\mathrm{X}) \text {, admitindo } \\
\text { p<0,05. Foram calculadas as } \\
\text { frequências absoluta e relativa } \\
(\%) \text { das características } \\
\text { sociodemográficas dos óbitos } \\
\text { por causas mal definidas. }\end{array}$ & $\begin{array}{l}\text { Regressão linear } \\
\text { segmentada }\end{array}$ & $\begin{array}{l}\text { Redução de } 88,5 \% \text { dos } \\
\text { óbitos por causas mal } \\
\text { definidas no Tocantins. A } \\
\text { análise de regressão linear } \\
\text { indicou tendência de } \\
\text { declínio da mortalidade } \\
\text { por causas mal definidas, } \\
\text { com pontos de inflexão } \\
\text { nos períodos } 1998-2004 \text { e } \\
\text { 2004-2014. Predominância } \\
\text { do sexo masculino, faixa } \\
\text { etária de } 60 \text { anos e mais, } \\
\text { raça/cor da pele parda, } \\
\text { estado civil solteiro e } \\
\text { nenhuma escolaridade. }\end{array}$ \\
\hline $\begin{array}{l}\text { (Ylijoki-Sørensen et } \\
\text { al., 2014) }\end{array}$ & $\begin{array}{l}\text { Estudo } \\
\text { transversal }\end{array}$ & $\begin{array}{l}\text { Amostra aleatória de } \\
90 \% \text { dos atestados de } \\
\text { óbito finlandeses e } \\
100 \% \text { dos } \\
\text { dinamarqueses } \\
\text { certificados dos registros } \\
\text { nacionais de mortalidade } \\
\text { para } 2000,2005 \text { e } 2010 .\end{array}$ & $\begin{array}{l}\text { Frequências de mortes } \\
\text { codificadas R00-R99 em } \\
\text { estatísticas de mortalidade. } \\
\text { Comparar os métodos usados } \\
\text { para } \\
\text { investigar a causa da morte. } \\
\text { As frequências de autópsias } \\
\text { médicas e forenses e exames }\end{array}$ & $\begin{array}{l}\text { IC } 95 \% \\
\mathrm{p}<0,001 . \text { Odds } \\
\text { ratio. }\end{array}$ & $\begin{array}{l}\text { O uso de códigos R00 - } \\
\text { R99 foi significativamente } \\
\text { maior na Dinamarca do } \\
\text { que na Finlândia; OR 18,6 } \\
\text { para 2000, OR 9,5 para } \\
2005 \text { e OR 13,2 para } 2010 . \\
\text { A autópsia forense foi } \\
\text { realizada em } 88,3 \% \text { das } \\
\text { mortes finlandesas, } \\
\end{array}$ \\
\hline
\end{tabular}




\begin{tabular}{|c|c|c|c|c|c|}
\hline & & & $\begin{array}{l}\text { clínicos externos dos corpos } \\
\text { em Mortes codificadas por } \\
\text { R00-R99. }\end{array}$ & & $\begin{array}{l}\text { enquanto apenas } 3,5 \% \text { das } \\
\text { mortes dinamarqueses } \\
\text { foram investigadas com } \\
\text { autópsia médica ou } \\
\text { forense. }\end{array}$ \\
\hline $\begin{array}{l}\text { (Rodrigues et al., } \\
2018 \text { ) }\end{array}$ & $\begin{array}{l}\text { Estudo ecológico } \\
\text { misto }\end{array}$ & $\begin{array}{l}\text { Todos os óbitos de } 15 \text { a } \\
59 \text { anos extraídos do } \\
\text { SIM, com definição de } \\
\text { causas mal definidas de } \\
\text { códigos R00-R99, } \\
\text { exceto R95, distúrbios } \\
\text { circulatórios mal } \\
\text { definidos (códigos I46.1, } \\
\text { I46.9, I95.9, I99), } \\
\text { distúrbios respiratórios } \\
\text { mal definidos (códigos } \\
\text { J96.0, J96.9) e } \\
\text { condições mal definidas } \\
\text { originarias no período } \\
\text { perinatal (código P28.5) }\end{array}$ & $\begin{array}{l}\text { Técnica de análise espacial. } \\
\text { Para verificar se há } \\
\text { dependência espacial, utilizou- } \\
\text { se o Moran I Global e o teste } \\
\text { de pseudo-significância para } \\
\text { dados assimétricos, que testou } \\
\text { se a proporção de causas mal } \\
\text { definidas de morte apresentava } \\
\text { maior similaridade nos estados } \\
\text { contíguos do Brasil do que } \\
\text { seria esperado ao acaso. }\end{array}$ & $\begin{array}{l}\text { Regressão de } \\
\text { Poisson } \\
\text { multinível }\end{array}$ & $\begin{array}{l}\text { De } 1998 \text { a 2012, houve } \\
\text { redução na proporção de } \\
\text { óbitos classificados como } \\
\text { mal definidos no Brasil, } \\
\text { sendo 1998-2002 (9\%), } \\
\text { 2003-2007 (8\%), 2008- } \\
2012(7 \%) \text {. Tanto homens } \\
\text { quanto mulheres } \\
\text { apresentaram a mesma } \\
\text { proporção no período. A } \\
\text { maior proporção foi nas } \\
\text { regiões Norte (14\%) e } \\
\text { Nordeste (12\%). Os } \\
\text { achados sugerem que } \\
\text { quanto menor a faixa } \\
\text { etária e melhor a condição } \\
\text { socioeconômica, menor o } \\
\text { risco de registrar a causa } \\
\text { da morte como mal } \\
\text { definida. }\end{array}$ \\
\hline (Iburg et al., 2020) & Estudo ecológico & $\begin{array}{l}\text { Todos os óbitos } \\
\text { registrados pelo Chief } \\
\text { Medical Office da } \\
\text { Groenlândia. }\end{array}$ & $\begin{array}{l}\text { Compreender o número de } \\
\text { mortes com código garbage } \\
\text { como inutilizável ou } \\
\text { insuficientemente } \\
\text { especificado. }\end{array}$ & & $\begin{array}{l}\text { As mortes por causas mal } \\
\text { definidas do capítulo } \\
\text { XVIII da CID-10 } \\
\text { correspondem a } 7 \%(\mathrm{~N}= \\
328) \text { de todas as mortes na } \\
\text { Groenlândia } \\
\text { e um quarto de todas as } \\
\text { causas inutilizáveis nos } \\
\text { últimos } 10 \text { anos } \\
\text { período. }\end{array}$ \\
\hline (Santo, 2008) & $\begin{array}{l}\text { Estudo ecológico } \\
\text { espacial }\end{array}$ & $\begin{array}{l}\text { Todos os óbitos } \\
\text { registrados } \\
\text { ( } \mathrm{n}=1.002 .340) \text { e com } \\
\text { causas mal definidas } \\
\text { (R00-R99) no SIM } \\
\text { ( } \mathrm{n}=133.434) \text {. As mortes } \\
\text { sem assistência (R98) } \\
\text { teve um } \mathrm{n}=71.120 .\end{array}$ & $\begin{array}{l}\text { As variáveis estudadas foram } \\
\text { causas básica e associadas de } \\
\text { morte, regiões e unidades da } \\
\text { federação de residência do } \\
\text { falecido. A distribuição dos } \\
\text { óbitos é descrita por meio de } \\
\text { percentagens. }\end{array}$ & & $\begin{array}{l}\text { Em 2003, os óbitos por } \\
\text { causas mal definidas no } \\
\text { Brasil foi } 13,3 \% \text {, os } \\
\text { maiores percentuais foram } \\
\text { n a região Nordeste } \\
(25,9 \%) \text { e a UF foi o } \\
\text { Maranhão }(37,4 \%) \text {. Em } \\
\text { relação aos óbitos sem } \\
\text { assistência médica o país } \\
\text { apresentou } 7,1 \%, \text { com a } \\
\text { região Nordeste com a } \\
\text { maior proporção (18,9\%) e } \\
\text { os estados do Maranhão, } \\
\text { Paraíba, Piauí e Rio } \\
\text { Grande do Norte com } \\
\text { valores superiores a } 20 \% \text {. } \\
\text { Minas Gerais apresentou } \\
\text { um percentual em relação } \\
\text { as causas mal definidas e } \\
\text { sem assistência médica de } \\
13 \% \text { e } 5,1 \%, \\
\text { respectivamente. }\end{array}$ \\
\hline $\begin{array}{l}\text { (Martins Junior et al., } \\
\text { 2011) }\end{array}$ & $\begin{array}{l}\text { Estudo } \\
\text { ecológico, do } \\
\text { tipo } \\
\text { exploratório de } \\
\text { múltiplos } \\
\text { grupos e de } \\
\text { séries temporais }\end{array}$ & $\begin{array}{l}\text { Todos os óbitos } \\
\text { registrados no capítulo } \\
\text { XVI da CID-9 e XVIII } \\
\text { da CID-10 (n= } \\
\text { 2.222.252), } \\
\text { desagregados por sexo, } \\
\text { faixa etária, local de } \\
\text { moradia (capital e } \\
\text { interior) }\end{array}$ & $\begin{array}{l}\text { A mortalidade proporcional por } \\
\text { causas mal definidas geral e } \\
\text { desagregada por sexo e por } \\
\text { faixa etária foi calculada. A } \\
\text { razão de tendência temporal } \\
\text { foi calculada para verificar o } \\
\text { comportamento das } \\
\text { proporções entre os períodos } \\
\text { determinados de } 5 \text { em } 5 \text { anos. } \\
\text { Variável independente (ano) e } \\
\text { variáveis dependentes } \\
\text { (proporção de óbitos total e } \\
\text { estratificada por sexo, capitais }\end{array}$ & $\begin{array}{l}\text { Regressão linear } \\
\text { simples }\end{array}$ & $\begin{array}{l}\text { A mortalidade por causas } \\
\text { mal definidas reduziu ao } \\
\text { longo das décadas, tendo o } \\
\text { menor percentual na } \\
\text { década de } 2000-2009 \\
(20,5 \%) \text {. Nessa região } \\
\text { evidenciou-se uma } \\
\text { tendência decrescente com } \\
\text { pequenas oscilações, tanto } \\
\text { global como nas capitais e } \\
\text { interior. Quanto ao sexo, } \\
\text { em ambos se observou } \\
\text { uma tendência decrescente }\end{array}$ \\
\hline
\end{tabular}




\begin{tabular}{|c|c|c|c|c|c|}
\hline & & & e interior). & & $\begin{array}{l}\text { em ambos os sexos, sendo } \\
\text { que a queda ocorreu } \\
\text { intercalando com alguns } \\
\text { períodos de aumento, e a } \\
\text { partir de } 1993 \text { apresenta } \\
\text { redução contínua. A } \\
\text { tendência também foi } \\
\text { decrescente no período em } \\
\text { todas as faixas etárias. }\end{array}$ \\
\hline $\begin{array}{l}(\text { Costa, Marli } \\
\text { Marcopito, 2008) }\end{array}$ & $\begin{array}{l}\text { Estudo ecológico } \\
\text { de séries } \\
\text { temporais }\end{array}$ & $\begin{array}{l}\text { Todos os óbitos por } \\
\text { causas mal definidas } \\
\text { agrupados por grandes } \\
\text { regiões brasileiras e por } \\
\text { UF e por faixa etária. }\end{array}$ & $\begin{array}{l}\text { 1) Gráficos de dispersão entre } \\
\text { porcentagem anual de óbitos } \\
\text { no total e por causas mal } \\
\text { definidas dentro de cada faixa } \\
\text { etária; } \\
\text { 2) Correlação paramétrica e } \\
\text { não-paramétrica por faixa } \\
\text { etária; } \\
\text { 3) Foram determinadas as } \\
\text { bandas que englobam } 90 \% \\
\text { dos valores observados de } \\
\text { porcentagem anual de óbitos } \\
\text { por causas mal definidas } \\
\text { dentro da faixa etária e no } \\
\text { total. }\end{array}$ & Regressão linear & $\begin{array}{l}\text { No país como um todo, } \\
\text { houve diminuição da } \\
\text { porcentagem de óbitos por } \\
\text { causas mal definidas a } \\
\text { partir de } 1985 \text {, saindo de } \\
\text { acima de } 20 \% \text { para em } \\
\text { torno de } 14 \% \text { em } 2002 \text {. } \\
\text { Houve redução gradual em } \\
\text { Minas Gerais (de perto de } \\
20 \% \text { para menos } 14 \% \text { ). A } \\
\text { faixa etária que apresentou } \\
\text { a mais crescente } \\
\text { contribuição percentual no } \\
\text { total de causas mal } \\
\text { definidas no país foi a de } \geq \\
50 \text { anos (de } 41,3 \% \text { em } \\
1979 \text { para } 84,3 \% \text { em } \\
2002 \text { ). A porcentagem } \\
\text { anual de mortes por todas } \\
\text { as causas ocorridas em } \\
\text { hospital exibiu relação } \\
\text { inversa com os óbitos por } \\
\text { causas mal definidas. }\end{array}$ \\
\hline (Kanso et al., 2011) & \begin{tabular}{|l} 
Estudo \\
transversal
\end{tabular} & $\begin{array}{l}\text { Todos os óbitos de idosos } \\
\text { acima de } 60 \text { anos. } \\
\text { Proporção de causas mal } \\
\text { definidas (códigos R00- } \\
\text { R99) }\end{array}$ & $\begin{array}{l}\text { As análises foram realizadas de } \\
\text { acordo com os seguintes níveis } \\
\text { de agregação: individual, área } \\
\text { geográfica de residência } \\
\text { segundo as regiões, UF, } \\
\text { capitais e municípios que não } \\
\text { pertencem à capital. }\end{array}$ & $\begin{array}{l}\text { Modelos } \\
\text { multinominais } \\
\text { hierárquicos não } \\
\text { ajustados e } \\
\text { foram } \\
\text { interpretados } \\
\text { com razões de } \\
\text { chance. }\end{array}$ & $\begin{array}{l}\text { A qualidade da informação } \\
\text { piora com o avanço da } \\
\text { idade dos idosos, sendo } \\
\text { acentuada piora a partir dos } \\
85 \text { anos, atingindo quase } \\
22 \% \text { dos óbitos dos idosos } \\
\text { com } 100 \text { anos ou mais de } \\
\text { idade. No Brasil, } 8,4 \% \text { das } \\
\text { causas de óbito foram } \\
\text { classificadas como mal } \\
\text { definidas, oscilando } \\
\text { acentuadamente entre UF e } \\
\text { regiões. Observaram-se } \\
\text { menores proporções de } \\
\text { causas mal definidas nas } \\
\text { capitais. } 38,5 \% \text { tiveram } \\
\text { morte sem assistência } \\
\text { médica (R98) e 35,2\% } \\
\text { foram outras causas mal } \\
\text { definidas e as não } \\
\text { especificadas de } \\
\text { mortalidade (R99). }\end{array}$ \\
\hline $\begin{array}{l}\text { (Kulhánová et al., } \\
\text { 2014) }\end{array}$ & $\begin{array}{l}\text { Estudo } \\
\text { longitudinal e } \\
\text { transversal }\end{array}$ & $\begin{array}{l}\text { Todos os óbitos por } \\
\text { causas de morte mal } \\
\text { definidas classificados } \\
\text { com códigos R00-R99 }\end{array}$ & $\begin{array}{l}\text { Dados de mortalidade de } 16 \\
\text { populações europeias coletados } \\
\text { e harmonizados no projeto } \\
\text { EURO-GBD-SE }\end{array}$ & $\begin{array}{l}\text { Testes de qui- } \\
\text { quadrado de } \\
\text { independência } \\
\text { para avaliar se a } \\
\text { proporção de } \\
\text { causas mal } \\
\text { definidas de } \\
\text { morte por grupo } \\
\text { educacional . } \\
\text { Todos os testes } \\
\text { foram realizados } \\
\text { com nível de } \\
\text { significância de } \\
5 \% \text {. }\end{array}$ & $\begin{array}{l}\text { A proporção de causas mal } \\
\text { definidas de morte foi } \\
\text { inferior a } 6,5 \% \text { entre os } \\
\text { homens e } 4,5 \% \text { entre as } \\
\text { mulheres em todos os } \\
\text { países europeus, sem } \\
\text { nenhum padrão geográfico } \\
\text { claro. Essa proporção } \\
\text { diferia estatisticamente de } \\
\text { forma significativa por } \\
\text { grupos educacionais em } \\
\text { vários países, com, na } \\
\text { maioria dos casos, uma } \\
\text { proporção mais alta entre } \\
\text { pessoas com menos de } \\
\text { ensino médio em } \\
\text { comparação com pessoas }\end{array}$ \\
\hline
\end{tabular}




\begin{tabular}{|c|c|c|c|c|c|}
\hline & & & & & com ensino superior. \\
\hline $\begin{array}{l}\text { (E. França et al., } \\
2020)\end{array}$ & $\begin{array}{l}\text { Estudo ecológico } \\
\text { de séries } \\
\text { temporais }\end{array}$ & $\begin{array}{l}\text { Todos os códigos } \\
\text { garbage foram } \\
\text { selecionados e } \\
\text { classificados em } 4 \\
\text { categorias. Os códigos } \\
\text { R, que eram } \\
\text { tradicionalmente } \\
\text { chamados de causas de } \\
\text { morte mal definidas } \\
\text { foram divididos em CG } \\
\text { de nível 1 e nível 2, } \\
\text { alguns códigos R não } \\
\text { foram classificados } \\
\text { como CG (R50.2, } \\
\text { R78.0-R78.5, R95). } \\
\text { Dados extraídos do SIM. }\end{array}$ & $\begin{array}{l}\text { Taxa de mortalidade CG de } \\
\text { cada tipo e índice } \\
\text { sociodemográficos foram } \\
\text { separados entre 1996-2005 e } \\
\text { 2006-2016. }\end{array}$ & Regressão linear & $\begin{array}{l}\text { As proporções de mortes } \\
\text { codificadas no nível } 1 \\
\text { caíram nesses anos de } 20,7 \\
\text { para } 12,5 \% \text { nos homens e } \\
\text { de } 25,1 \text { para } 14 \% \text { nas } \\
\text { mulheres. Nos menores de } \\
50 \text { anos predomina o nível } \\
1 \text { dos CG. As proporções } \\
\text { mais altas dos principais } \\
\text { níveis } 1 \text { e } 2 \text { estavam } \\
\text { presentes nas mortes } \\
\text { ocorridas em casa. Todos } \\
\text { os estados brasileiros } \\
\text { tinham baixas de níveis de } \\
\text { CG } 1 \text { e } 2 \text { em } 2016 \text { em } \\
\text { comparação com } 1996 . \text { As } \\
\text { taxas padronizadas por } \\
\text { idade dos níveis de CG } 1 \text { e } \\
2 \text { diminuíram à medida } \\
\text { que índice } \\
\text { sociodemográfico } \\
\text { aumentou para os estados. }\end{array}$ \\
\hline $\begin{array}{l}\text { (E. França et al., } \\
2008)\end{array}$ & $\begin{array}{l}\text { Estudo } \\
\text { transversal }\end{array}$ & $\begin{array}{l}\text { Todos os óbitos } \\
\text { registrados no SIM }\end{array}$ & $\begin{array}{l}\text { Avaliado a proporção de causas } \\
\text { mal definidas e códigos não } \\
\text { específicos, oportunidade e } \\
\text { desagregação geográfica foram } \\
\text { usados para avaliar os } \\
\text { atributos da qualidade dos } \\
\text { dados. }\end{array}$ & & $\begin{array}{l}13,1 \% \text { de todas as mortes } \\
\text { foram atribuídas à causa } \\
\text { mal definida no Brasil em } \\
2002-2004, \text { e é } \\
\text { responsável por quase um } \\
\text { quarto de todas as mortes } \\
\text { no Norte e Nordeste. } \\
\text { Quanto à oportunidade e a } \\
\text { usabilidade das estatísticas } \\
\text { para fins subnacionais } \\
\text { foram consideradas } \\
\text { razoáveis e aumentam a } \\
\text { confiança no uso das } \\
\text { estatísticas. }\end{array}$ \\
\hline (Ishitani et al., 2017) & $\begin{array}{l}\text { Estudo } \\
\text { transversal }\end{array}$ & $\begin{array}{l}\text { Total de óbitos ( } \mathrm{n}= \\
44.123) \text { e óbitos } \\
\text { classificados como } \\
\text { códigos garbage }(\mathrm{n}= \\
\text { 13.438). Esses códigos } \\
\text { foram agrupados em: } \\
\text { CG do capítulo XVIII da } \\
\text { CID-10 (códigos R00- } \\
\text { R99) e CG de outros } \\
\text { capítulos da CID-10. }\end{array}$ & $\begin{array}{l}\text { Proporção de CG, desagregados } \\
\text { nos agrupamentos CG-códigos } \\
\text { R e CG-códigos não R. perfil } \\
\text { dos óbitos por sexo, idade e } \\
\text { local de ocorrência do óbito. }\end{array}$ & & $\begin{array}{l}\text { 30,5\% dos óbitos foram por } \\
\text { CG total e 5,5\% por CG- } \\
\text { códigos R. Do total de } \\
\text { CG- códigos R } 54,5 \% \\
\text { ocorreram em domicílio. } \\
\text { A principal causa de morte } \\
\text { entre todos os óbitos foi } \\
\text { R99 (Outras causas mal } \\
\text { definidas e as não } \\
\text { especificadas de } \\
\text { mortalidade) com } 4,9 \% \text {. }\end{array}$ \\
\hline $\begin{array}{l}\text { (Martins Junior et al., } \\
2016)\end{array}$ & $\begin{array}{l}\text { Estudo ecológico } \\
\text { de séries } \\
\text { temporais e } \\
\text { análises } \\
\text { exploratórias }\end{array}$ & $\begin{array}{l}\text { Todos os óbitos } \\
\text { registrados como causas } \\
\text { mal definidas entre } \\
\text { idosos no SIM }(\mathrm{n}= \\
\text { 2.646.194). }\end{array}$ & $\begin{array}{l}\text { Tendência temporal da } \\
\text { mortalidade por causas mal } \\
\text { definidas entre os idosos como } \\
\text { variável independente o ano- } \\
\text { calendário como variável } \\
\text { dependente causas mal } \\
\text { definidas globais e separadas } \\
\text { por sexo e região geográfica. }\end{array}$ & $\begin{array}{l}\text { Regressão linear } \\
\text { simples }\end{array}$ & $\begin{array}{l}\text { Houve queda significativa } \\
\text { na proporção de causas } \\
\text { mal definidas de morte } \\
\text { entre idosos no Brasil em } \\
\text { geral, passando de } 20,7 \% \\
\text { em } 1979 \text { para } 6,2 \% \text { em } \\
\text { 2013. A tendência da } \\
\text { mortalidade proporcional } \\
\text { por causas mal definidas } \\
\text { entre idosos diminuiu } \\
\text { tanto para o Brasil quanto } \\
\text { para as macrorregiões. }\end{array}$ \\
\hline
\end{tabular}




\begin{tabular}{|c|c|c|c|c|c|}
\hline $\begin{array}{l}\text { (Özdemir et al., } \\
\text { 2015) }\end{array}$ & $\begin{array}{l}\text { Estudo ecológico } \\
\text { dos dados da } \\
\text { Turquia e } \\
\text { Estudo } \\
\text { Transversal de } \\
\text { dados de Izmir } \\
\text { em } 2010\end{array}$ & $\begin{array}{l}\text { Todos os óbitos por } \\
\text { idade, sexo e grupos de } \\
\text { cinco anos para cada ano } \\
\text { de } 2001 \text { a } 2013 \text {. } \\
\text { As variáveis individuais } \\
\text { registradas nas } \\
\text { declarações de óbito de } \\
\text { Izmir (n=18.933) }\end{array}$ & $\begin{array}{l}\text { A qualidade das estatísticas de } \\
\text { mortalidade foi avaliada em } \\
\text { duas grandes dimensões; um } \\
\text { relacionado à generalização } \\
\text { dos dados, em termos de } \\
\text { completude do registro de } \\
\text { óbito; e a segunda, uma } \\
\text { avaliação da validade das } \\
\text { causas relatadas de morte, em } \\
\text { termos da proporção de mortes } \\
\text { atribuídas por causas mal } \\
\text { definidas. }\end{array}$ & & $\begin{array}{l}\text { A avaliação dos dados de } \\
\text { mortalidade na Turquia } \\
\text { demostram uma melhora } \\
\text { na última década, nas duas } \\
\text { dimensões importantes de } \\
\text { completude do registro de } \\
\text { óbito, bem como na } \\
\text { especificação das causas } \\
\text { de óbito. } \\
\text { A proporção de causa de } \\
\text { morte mal definida em } \\
\text { Izmir foi observada mais } \\
\text { elevadas para o sexo } \\
\text { feminino, para os óbitos } \\
\text { em casa e } 1 / 3 \text { de todas as } \\
\text { mortes nas faixas etárias } \\
\text { de } 15 \text { a } 59 \text { anos são } \\
\text { codificadas para condições } \\
\text { mal definidas. }\end{array}$ \\
\hline (Paes, 2007) & $\begin{array}{l}\text { Estudo } \\
\text { transversal }\end{array}$ & $\begin{array}{l}\text { Todos os óbitos por } \\
\text { causas mal definidas do } \\
\text { capítulo XVI da CID-9 e } \\
\text { XVIII da CID-10 da } \\
\text { população adulta das UF } \\
\text { do Brasil }\end{array}$ & $\begin{array}{l}\text { Percentual de óbitos por causas } \\
\text { mal definidas por UF, por sexo } \\
\text { e classificada qualidade quanto } \\
\text { adequado }(<10 \%) \text {, pouco } \\
\text { adequado }(10 \%-15 \%), \\
\text { inadequado }(16 \%-30 \%) \text { e } \\
\text { altamente inadequado }(>30 \%) \text {. }\end{array}$ & & $\begin{array}{l}\text { O percentual de óbitos por } \\
\text { causas mal definidas em } \\
\text { homens passou de } 13 \% \\
\text { para } 13,9 \% \text { e nas mulheres } \\
\text { passou de } 14,4 \% \text { para } \\
15,4 \% \text { no país. Em Minas } \\
\text { Gerais, a classificação } \\
\text { para os homens se } \\
\text { manteve regular, enquanto } \\
\text { para as mulheres atingiu a } \\
\text { classificação satisfatória } \\
\text { em 2000. A relação entre o } \\
\text { percentual de urbanização } \\
\text { com o percentual das mal } \\
\text { definidas apontou } \\
\text { coeficiente com sinal } \\
\text { inverso, da ordem de }-0,77 \\
\text { para homens e de }-0,69 \\
\text { para mulheres. }\end{array}$ \\
\hline $\begin{array}{l}\text { (M. S. Lima et al., } \\
\text { 2020) }\end{array}$ & $\begin{array}{l}\text { Estudo ecológico } \\
\text { exploratório de } \\
\text { tendências } \\
\text { temporais }\end{array}$ & $\begin{array}{l}\text { Para a análise temporal } \\
\text { das causas mal definidas } \\
\text { de morte, foram } \\
\text { selecionados os casos } \\
\text { com os códigos R69, } \\
\text { R98 e R99 com base na } \\
\text { CID-10. }\end{array}$ & $\begin{array}{l}\text { Intervalos de confiança de } 95 \% \\
\text { e valores de } \mathrm{p} \text {. Uma mudança } \\
\text { significativa em uma tendência } \\
\text { foi definida como } \mathrm{p}<0,05 \text {. }\end{array}$ & $\begin{array}{l}\text { As curvas } \\
\text { modeladas pelo } \\
\text { Joinpoint. }\end{array}$ & $\begin{array}{l}\text { A curva de tendências das } \\
\text { causas mal definidas de } \\
\text { RAS apresentou queda } \\
\text { estatisticamente } \\
\text { significativa desde o início } \\
\text { da série até } 2006 \text { e } \\
\text { estabilizou posteriormente }\end{array}$ \\
\hline (Jorge et al., 2008) & $\begin{array}{l}\text { Estudo } \\
\text { transversal }\end{array}$ & $\begin{array}{l}\text { A população de estudo } \\
\text { são os óbitos por causas } \\
\text { mal definidas, contidas } \\
\text { nos capítulo XVIII da } \\
\text { CID-10 em idosos acima } \\
\text { de } 60 \text { anos. }\end{array}$ & $\begin{array}{l}\text { A análise foi feita de acordo } \\
\text { com sexo, idade, assistência } \\
\text { médica durante a doença que } \\
\text { levou à morte, local de } \\
\text { ocorrência do óbito e } \\
\text { qualidade do médico que } \\
\text { forneceu a DO e causa básica } \\
\text { de morte. }\end{array}$ & & $\begin{array}{l}\text { No Brasil, as proporções de } \\
\text { óbitos por causas mal } \\
\text { definidas mostram } \\
\text { reduções relevantes entre } \\
1996 \text { e } 2005 \text { de } 15,1 \text { para } \\
10,4 \% \text { em todas as idades } \\
\text { e de } 18,2 \text { para } 11,9 \% \text { em } \\
\text { idosos de } 60 \text { anos e mais. } \\
\text { Quanto à variável } \\
\text { Assistência médica e suas } \\
\text { modalidade, nota-se que } \\
75 \% \text { dos casos, havia sido } \\
\text { preenchida a categoria } \\
\text { ignorada ou nenhuma } \\
\text { delas estava assinalada. O } \\
\text { local de ocorrência dos } \\
\text { óbitos mal definidos dos } \\
\text { idosos, destaca-se a } \\
\text { categoria domicílio em } \\
\text { proporções superiores a } \\
70 \%, \text { chegando a } 77 \% \\
\text { entre } 1996 \text { e } 2005 .\end{array}$ \\
\hline
\end{tabular}




\begin{tabular}{|c|c|c|c|c|c|}
\hline $\begin{array}{l}\text { (E. E. C. De Lima \& } \\
\text { Queiroz, 2014) }\end{array}$ & $\begin{array}{l}\text { Estudo ecológico } \\
\text { espacial }\end{array}$ & $\begin{array}{l}\text { As informações de óbitos } \\
\text { e causas mal definidas } \\
\text { de morte são fornecidas } \\
\text { pela CID-9 e CID-10. }\end{array}$ & $\begin{array}{l}\text { Relação entre as mudanças na } \\
\text { porcentagem de causas mal } \\
\text { definidas de morte e as } \\
\text { mudanças na porcentagem de } \\
\text { completude da cobertura de } \\
\text { contagens de morte e na } \\
\text { porcentagem de mortes acima } \\
\text { de } 65 \text { anos. }\end{array}$ & Regressão linear & $\begin{array}{l}\text { O percentual de causas mal } \\
\text { definidas de morte reduziu } \\
\text { cerca de } 53 \% \text { no país. O } \\
\text { número de mesorregiões } \\
\text { com mais de } 20 \% \text { das } \\
\text { mortes registradas como } \\
\text { mal definidas reduziu } \\
\text { significativamente em } \\
\text { todo o país. Melhorias na } \\
\text { coleta de dados de } \\
\text { contagens de mortes } \\
\text { parecem ocorrer } \\
\text { juntamente com melhorias } \\
\text { nos relatórios de causas de } \\
\text { morte. }\end{array}$ \\
\hline $\begin{array}{l}\text { (E. E. C. de Lima \& } \\
\text { Queiroz, 2011) }\end{array}$ & $\begin{array}{l}\text { Estudo ecológico } \\
\text { espacial }\end{array}$ & $\begin{array}{l}\text { As informações de } \\
\text { mortalidade } \\
\text { correspondem às } 75 \\
\text { regiões de saúde do } \\
\text { Estado de Minas Gerais. } \\
\text { Os óbitos por causas mal } \\
\text { definidas do capítulo } \\
\text { XVI da CID-9 e XVIII } \\
\text { da CID-10 }\end{array}$ & $\begin{array}{l}\text { Relação dos riscos relativos de } \\
\text { morte por causas mal definidas } \\
\text { e cobertura de óbitos. }\end{array}$ & $\begin{array}{l}\text { Tendência não- } \\
\text { paramétricas. } \\
\text { Cobertura entre } \\
1980-1991 \text { e } \\
\text { risco relativo } \\
\text { em 1991; } \\
\text { cobertura entre } \\
1991-2000 \text { e } \\
\text { risco relativo } \\
\text { em 2000; } \\
\text { cobertura entre } \\
\text { 2000-2006 e } \\
\text { risco relativo } \\
\text { em 2007. }\end{array}$ & $\begin{array}{l}\text { Entre } 1980 \text { e } 1991, \text { a } \\
\text { qualidade dos registros } \\
\text { ficava em torno de } 85 \% \text { a } \\
90 \% \text {, passando para } 95 \%, \\
\text { em } 2000 \text {, e para quase } \\
100 \% \text { em 2006. Entre } \\
1980 \text { e } 2007, \text { os focos dos } \\
\text { clusters permaneceram } \\
\text { concentrados no norte e } \\
\text { nordeste mineiros. } \\
\text { Houve considerável } \\
\text { aumento do nível de } \\
\text { registro de óbitos } \\
\text { juntamente com } \\
\text { crescimento dos riscos } \\
\text { relativos de óbitos por } \\
\text { causas mal definidas. }\end{array}$ \\
\hline (Abreu et al., 2010) & $\begin{array}{l}\text { Estudo } \\
\text { transversal }\end{array}$ & $\begin{array}{l}\text { Todos os óbitos mal } \\
\text { definidos do capítulo } \\
\text { XVIII da CID-10 em } \\
\text { idosos acima de } 60 \text { anos }\end{array}$ & $\begin{array}{l}\text { Para descrição do perfil } \\
\text { sociodemográfico utilizou-se o } \\
\text { IDH. }\end{array}$ & $\begin{array}{l}\text { Causa de morte } \\
\text { no capítulo } \\
\text { CMD e a } \\
\text { ocorrência do } \\
\text { óbito em } \\
\text { hospitais } \\
\text { avaliada pelo } \\
\text { Odds ratio }\end{array}$ & $\begin{array}{l}\text { Os óbitos por CMD estão } \\
\text { mais concentrados nas } \\
\text { idades mais avançadas } \\
\text { (acima de } 80 \text { anos), } \\
\text { particularmente para as } \\
\text { mulheres, nas capitais } \\
\text { selecionadas. } \\
\text { A classificação do óbito } \\
\text { como CMD mostrou-se } \\
\text { negativamente associada à } \\
\text { ocorrência em hospital. }\end{array}$ \\
\hline $\begin{array}{l}\text { (Santos \& Rodrigues, } \\
\text { 2019) }\end{array}$ & $\begin{array}{l}\text { Estudo } \\
\text { transversal }\end{array}$ & $\begin{array}{l}\text { Óbitos por município de } \\
\text { ocorrência. Óbito por } \\
\text { causa mal definida } \\
\text { classificada em } 4 \text { grupos } \\
\text { com base na CID-10: } \\
\text { códigos R00-R94 e R96- } \\
\text { R99; código J96.0; } \\
\text { código J96.9; código } \\
\text { P28.5. Dados extraídos } \\
\text { do SIM. }\end{array}$ & $\begin{array}{l}\text { Para analisar a qualidade da } \\
\text { informação do sistema } \\
\text { utilizou-se a proporção de } \\
\text { óbitos por causas mal } \\
\text { definidas. }\end{array}$ & & $\begin{array}{l}\text { O percentual de óbitos por } \\
\text { causas mal definidas } \\
\text { variou de } 3,66 \% \text { no } \\
\text { município de Venturosa a } \\
52,08 \% \text { em Buíque. }\end{array}$ \\
\hline
\end{tabular}

Fonte: Autores.

Quanto à qualidade metodológica em relação à caracterização e ao tamanho da população ou da amostra, 21 estudos descreveram a população como os óbitos totais e por causas mal definidas em números absolutos ou percentuais e 01 publicação utilizou amostra, sendo de atestados aleatórios (Ylijoki-Sørensen et al., 2014). A avaliação do desfecho mortalidade proporcional por causas mal definidas - foi aferida através de percentual calculado pelo número de óbitos por causas mal definidas dividido por número total de óbitos multiplicado por 100. Em relação à análise estatística, 14 estudos descreveram as técnicas estatísticas empregadas, sendo 02 modelo de regressão logística multinominal hierárquica, 01 regressão de Poisson multinível, 01 regressão linear segmentada, 05 regressão linear simples, 01 curvas modeladas pelo 
Joinpoint, 02 tendências não-paramétricas, 02 teste qui-quadrado, 04 odds ratio, 04 intervalo de confiança de $95 \%$ e $p<0,05$. Nenhum estudo foi excluído pela qualidade metodológica.

A redação dos artigos detalha o referencial teórico e a justificativa para a execução do estudo, os objetivos, o delineamento, contexto e caracterização da população ou amostra, os critérios de elegibilidade, as fontes e métodos de seleção dos participantes, os principais resultados e associações quando trabalhadas e discute os achados com base na literatura. No entanto, vários estudos suprimiram o período de coleta de dados secundários, o que não comprometeu a utilização dos estudos.

Estudos recentes ampliaram as análises para além das causas básicas de morte do capítulo XVIII da CID-10, abordando os Códigos Garbage (CG) que consistem em diagnósticos que não deveriam ser considerados como causa básica de óbito por serem pouco úteis para as políticas públicas de saúde, já que não permitem identificar adequadamente ações para prevenção e controle de doenças e agravos de saúde. Este novo entendimento surgiu com a rede de estudos da Carga Global de Doenças (Global Burden of Disease - GBD). Considerando os níveis de impacto desses códigos para a avaliação e o planejamento das políticas públicas em saúde, os códigos R do CID-10 estão inclusos no Nível 1 - Códigos com implicações graves que provavelmente possuem um impacto MUITO ALTO, pois esses códigos não podem ser direcionados a nenhum dos três grandes grupos de causas definidos pelo estudo GBD (doenças transmissíveis, maternas, neonatais e nutricionais; doenças crônicas não transmissíveis, incluindo condições de saúde mental; e, causas externas) (Brasil, 2019; Iburg et al., 2020).

A mortalidade proporcional por causas mal definidas em todos os estudos de série temporais apresentaram redução ao longo do tempo no Brasil e nas regiões. Os fatores que podem ter influenciado na queda da mortalidade foram a implantação do Sistema Único de Saúde (SUS) em 1988, os programas de saúde da família em 1994, incentivo governamental para profissionais de saúde atuarem em cidades menores e áreas remotas, maior cobertura do SIM no país e capacitação de codificadores e seletores de causas básicas de morte (E. E. C. De Lima \& Queiroz, 2014; M. S. Lima et al., 2020). Porém percebe-se que quando comparada com outros países essas taxas ainda tem uma relevante magnitude, além de uma disparidade entre as regiões, unidades federativas, capitais e municípios. Estudo realizado em 2016 verificou que 19,2\% dos municípios brasileiros foram classificados quanto à proporção de óbitos por CMD como inadequado ou altamente inadequado, ou seja, com mortalidade proporcional por CMD superior a 10\% (Muzy et al., 2021). Possíveis motivos do preenchimento inadequado das causas básicas de óbito podem ser a falta de recursos de diagnóstico em alguns locais, tanto físicos quanto humanos, pois a rede de atenção, os serviços e a tecnologia disponíveis são peças-chave para a definição das causas de óbito (Muzy et al., 2021).

Nesta revisão identificou-se que apenas 02 estudos abordaram a análise por microrregião de saúde, sendo um em Minas Gerais com avaliação dos dados de 1980 a 2007 (E. E. C. de Lima \& Queiroz, 2011) e outro no Pernambuco em 2013 (Santos \& Rodrigues, 2019). Observada essa lacuna e compreendendo que a rede assistência e os dispositivos de saúde disponíveis são fundamentais para garantia de uma atenção integral, percebe-se a necessidade de mais estudos voltados aos espaços geográficos das macro e microrregiões de saúde. Vale destacar a limitação da precisão da totalidade da produção científica, visto que a literatura cinza é um elemento que impede essa afirmação.

Os resultados dos estudos apontam que a maioria dos óbitos por causas mal definidas ocorrem nos domicílios (Abreu et al., 2010; Costa, Marli Marcopito, 2008; E. França et al., 2020; Ishitani et al., 2017; Jorge et al., 2008). É provável que os percentuais de óbitos por causas mal definidas diminuem à medida que aumente o acesso à assistência médica na situação de risco de morte, particularmente em ambiente hospitalar - onde existem, em teoria, mais recursos diagnósticos (Costa, Marli Marcopito, 2008), pois a maior proporção de óbitos domiciliares pode ser devido a dificuldades de diagnóstico ou a falta de conhecimento do diagnóstico por parte do médico (E. França et al., 2020). Dados divergentes foram observados na coorte de Bambuí em que óbitos aconteceram em maior proporção no hospital (Lima-Costa et al., 2010). Vale destacar que os delineamentos dos estudos selecionados foram diferentes deste último. 
Os estudos certificaram que o percentual de óbitos por causas mal definidas aumenta com a idade, principalmente nos idosos (Abreu et al., 2010; Jorge et al., 2008; Kanso et al., 2011; Martins Junior et al., 2011; Rodrigues et al., 2018) e a escolaridade se mostra inversamente proporcional a estes óbitos (Balieiro et al., 2020; Kulhánová et al., 2014; Prestes et al., 2018). A educação está entre os fatores determinantes e condicionantes da saúde, portanto a baixa escolaridade pode comprometer o autocuidado do idoso (Borba et al., 2019). E ainda pessoas com níveis de escolaridade mais elevados podem possuir melhor acesso a bens e serviços de saúde (Belém et al., 2016). Uma estratégia para enfrentar essa situação seria a literacia em saúde na Atenção Primária à Saúde (Boitrago et al., 2021).

Os achados apresentados sinalizam que o acesso e qualidade do serviço de saúde devem ser levados em consideração nas análises desses óbitos. O acesso é uma dimensão do desempenho dos sistemas de saúde associada à oferta e trata-se de um importante determinante do uso do serviço, este pode ser influenciado por fatores individuais predisponentes, fatores contextuais e relativos à qualidade do cuidado, entre outras particularidades (Travassos \& Martins, 2004).

O monitoramento, acompanhamento e investigação dos óbitos por causas mal definidas proporciona a melhoria do indicador como informado nos artigos selecionados (E. E. C. De Lima \& Queiroz, 2014; R. B. de Lima et al., 2019; Jorge et al., 2008; Özdemir et al., 2015; Ylijoki-Sørensen et al., 2014). A investigação dos óbitos sem definição de causa básica permite estimativas mais adequadas do risco de mortalidade por causas específicas, valorização do esforço e trabalho da equipe de vigilância do óbito, no entanto deve ser mais incentivado o papel do médico e sua participação no preenchimento adequado da declaração de óbito (E. França et al., 2014). Essas estratégias favorecem a melhoria da qualidade da informação que serve de base para o planejamento em todos os níveis (Cunha et al., 2017, 2019; E. B. França et al., 2014).

\section{Considerações Finais}

Conclui-se que a mortalidade proporcional por causas mal definidas reduziu ao longo do tempo no Brasil, porém apresenta importante magnitude, além das disparidades entre regiões, unidades federativas, capitais e municípios do interior. Quanto ao perfil identificou-se que os óbitos foram, predominantemente, em idosos, pessoas com baixa escolaridade, ocorridos em casa e que as investigações contribuem para a melhoria da qualidade da informação.

Portanto, a revisão integrativa a respeito da mortalidade e perfil epidemiológico dos óbitos por causas mal definidas disponíveis na literatura científica permitiu aprofundar sobre a temática e constatar a necessidade de novas pesquisas em unidades geográficas menores como, por exemplo, municípios, micro e macrorregiões de saúde. O estudo também permitiu a atualização e acompanhamento da taxa de mortalidade proporcional por causas mal definidas e identificação dos fatores relacionados à qualidade da informação, ao acesso aos serviços de saúde e aos fatores determinantes e condicionantes do não fechamento do diagnóstico em alguns grupos populacionais.

Por fim, entendo as implicações das mortes por causas mal definidas na compreensão do cenário epidemiológico nos diversos territórios, nas implementações das políticas públicas e na tomada de decisão pelos gestores, espera-se que trabalhos futuros de avaliação da qualidade de informação das declarações de óbito sejam realizadas, levando-se em consideração o perfil dos profissionais responsáveis pelo preenchimento, à população mais vulnerável em relação ao acesso e à qualidade assistencial.

\section{Agradecimentos}

Nossa gratidão e reconhecimento pelas contribuições fornecidas pelos docentes do Mestrado Profissional em Saúde, Sociedade e Ambiente (SaSA) da Universidade Federal dos Vales do Jequitinhonha e Mucuri (UFVJM) para realização deste trabalho. 


\section{Referências}

Abreu, D. M. X. de, Sakurai, E., \& Campos, L. N. (2010). A evolução da mortalidade por causas mal definidas na população idosa em quatro capitais brasileiras, 1996-2007. Revista Brasileira de Estudos de População, 27(1), 75-88. https://doi.org/10.1590/S0102-30982010000100006

Balieiro, P. C. da S., da Silva, L. C. F., Sampaio, V. de S., Monte, E. X. Do, Pereira, E. M. D. S., de Queiroz, L. A. F., Saraiva, R., \& Costa, A. J. L. (2020). Factors associated with unspecified and ill-defined causes of death in the state of Amazonas, Brazil, from 2006 to 2012. Ciencia e Saude Coletiva, 25(1), 339352. https://doi.org/10.1590/1413-81232020251.27182017

Belém, P. L. de O., Melo, R. L. P. de, Pedraza, D. F., \& Menezes, T. N. de. (2016). Autoavaliação do estado de saúde e fatores associados em idosos cadastrados na Estratégia Saúde da Família de Campina Grande, Paraíba. Revista Brasileira de Geriatria e Gerontologia, 19(2), 265-276. https://doi.org/10.1590/1809-98232016019.140206

Boitrago, S. C. O. de S., Souza, A. S. O., Cunha, P. de O., Vieira, M. A., Caldeira, A. P., Carneiro, J. A., \& Costa, F. M. da. (2021). Mortality in communitydwelling elderly: coefficient and associated factors. Revista Brasileira de Enfermagem, 74(suppl 2). https://doi.org/10.1590/0034-7167-2020-0612

Borba, A. K. de O. T., Arruda, I. K. G., Marques, A. P. de O., Leal, M. C. C., \& Diniz, A. da S. (2019). Conhecimento sobre o diabetes e atitude para o autocuidado de idosos na atenção primária à saúde. Ciência \& Saúde Coletiva, 24(1), 125-136. https://doi.org/10.1590/1413-81232018241.35052016

Brasil. (2009). PORTARIA N 116 , DE 11 DE FEVEREIRO DE 2009 Regulamenta a coleta de dados, fluxo e periodicidade de envio das informações sobre óbitos e nascidos vivos para os Sistemas de Informações em Saúde sob gestão da Secretaria de Vigilância em Saúde. (pp. 1-20). Diário Oficial da União.

Brasil. (2018). Agenda de Prioridades de Pesquisa do Ministério da Saúde - APPMS [recurso eletrônico]. http://bvsms.saude.gov.br/bvs/publicacoes/agenda_prioridades_pesquisa_ms.pdf

Brasil. (2019). Health Brazil 2018: An analysis of the health situation and of chronic diseases and conditions: challenges and perspectives (p. 424 p.). https://bvsms.saude.gov.br/bvs/publicacoes/saude_brasil_2018_analise_situacao_saude_doencas_agravos_cronicos_desafios_perspectivas.pdf

Costa, Marli Marcopito, L. (2008). Mortalidade por causas mal defi nidas , Brasil , 1979-2002, e um modelo preditivo para idade Mortality due to ill-defi ned causes in Brazil ( 1979-2002 ) and a predictive model for age. Rev Assoc Med Bras, 24(5), 1001-1012.

Cunha, C. C. da, Teixeira, R., \& França, E. (2017). Avaliação da investigação de óbitos por causas mal definidas no Brasil em 2010. Epidemiologia e Servicos de Saude : Revista Do Sistema Unico de Saude Do Brasil, 26(1), 19-30. https://doi.org/10.5123/S1679-49742017000100003

Cunha, C. C. da, Vasconcelos, A. M. N., Souza, M. de F. M. de, \& França, E. (2019). Avaliação da investigação de óbitos por causas mal definidas no estado da Bahia, Brasil, em 2010. Ciencia \& Saude Coletiva, 24(5), 1831-1844. https://doi.org/10.1590/1413-81232018245.14852017

de Lima, E. E. C., \& Queiroz, B. L. (2011). A evolução do sub-registro de mortes e causas de óbitos mal definidas em minas gerais: Diferenciais regionais. Revista Brasileira de Estudos de Populacao, 28(2), 303-320. https://doi.org/10.1590/S0102-30982011000200004

De Lima, E. E. C., \& Queiroz, B. L. (2014). A evolução do sistema de registro de mortalidade no brasil: Mudanças no perfil de mortalidade, cobertura do registro de óbitos e as causas mal definidas de morte. Cadernos de Saude Publica, 30(8), 1721-1730. https://doi.org/10.1590/0102-311X00131113

de Lima, R. B., Frederes, A., Marinho, M. F., Da Cunha, C. C., Adair, T., \& França, E. B. (2019). Investigation of garbage code deaths to improve the quality of cause-of-death in Brazil: Results from a pilot study. Revista Brasileira de Epidemiologia, 22. https://doi.org/10.1590/1980-549720190004.supl.3

França, E. B., , Carolina Cândida da Cunha, A. M. N. V., Juan José Cortez Escalante, D. X. de A., LimaIV, R. B. de, \& Neto, O. L. de M. (2014). Avaliação da implantação do programa "Redução do percentual de óbitos por causas mal definidas" em um estado do Nordeste do Brasil Investigation of ill-defined causes of death: assessment of a program's performance in a State from the Northeastern region . Rev Bras Epidemiol, Jan-Mar, 119-134. https://doi.org/10.1590/1415-790X201400010010

França, E., De Abreu, D. X., Rao, C., \& Lopez, A. D. (2008). Evaluation of cause-of-death statistics for Brazil, 2002-2004. International Journal of Epidemiology, 37(4), 891-901. https://doi.org/10.1093/ije/dyn121

França, E., Ishitani, L. H., Teixeira, R., Duncan, B. B., Marinho, F., \& Naghavi, M. (2020). Changes in the quality of cause-of-death statistics in Brazil: Garbage codes among registered deaths in 1996-2016. Population Health Metrics, 18(Suppl 1), 1-13. https://doi.org/10.1186/s12963-020-00221-4

França, E., Teixeira, R., Ishitani, L., Duncan, B. B., Cortez-Escalante, J. J., Morais Neto, O. L. de, \& Szwarcwald, C. L. (2014). Ill-defined causes of death in Brazil: a redistribution method based on the investigation of such causes. Revista de Saúde Pública, 48(4), 671-681. https://doi.org/10.1590/S00348910.2014048005146

Galvão, T. F., \& Pereira, M. G. (2014). Revisões sistemáticas da literatura: passos para sua elaboração. Epidemiologia e Serviços de Saúde, 23(1), 183-184. https://doi.org/10.5123/S1679-49742014000100018

Iburg, K. M., Mikkelsen, L., \& Richards, N. (2020). Assessment of the quality of cause-of-death data in Greenland, 2006-2015. Scandinavian Journal of Public Health, 48(8), 801-808. https://doi.org/10.1177/1403494819890990

Ishitani, L. H., Teixeira, R. A., Abreu, D. M. X., Paixão, L. M. M. M., \& França, E. B. (2017). Qualidade da informação das estatísticas de mortalidade: Códigos garbage declarados como causas de morte em Belo Horizonte, 2011-2013. Revista Brasileira de Epidemiologia, 20 , 34-45. https://doi.org/10.1590/1980-5497201700050004

Jorge, M. H. P. de M., Laurenti, R., Lima-Costa, M. F., Gotlieb, S. L. D., \& Filho, A. D. P. C. (2008). A mortalidade de idosos no Brasil: a questão das causas mal definidas. Epidemiologia e Serviços de Saúde, 17(4), 271-281. https://doi.org/10.5123/s1679-49742008000400004

Kanso, S., Romero, D. E., da Costa Leite, I., \& de Moraes, E. N. (2011). Diferenciais geográficos, socioeconômicos e demográficos da qualidade da informação da causa básica de morte dos idosos no Brasil. Cadernos de Saude Publica, 27(7), 1323-1339. https://doi.org/10.1590/S0102$311 \times 2011000700008$ 
Kulhánová, I., Menvielle, G., Bopp, M., Borrell, C., Deboosere, P., Eikemo, T. A., Hoffmann, R., Leinsalu, M., Martikainen, P., Regidor, E., Rodríguez-Sanz, M., Rychtaříková, J., Wojtyniak, B., \& Mackenbach, J. P. (2014). Socioeconomic differences in the use of ill-defined causes of death in 16 European countries. BMC Public Health, 14(1), 1-8. https://doi.org/10.1186/1471-2458-14-1295

Laurenti, Ruy; Jorge, M. H. P. de M. (2015). O Atestado de obito.pdf (Conselho Regional de Medicina do Estado de São Paulo (ed.)).

Lima-Costa, M. F., Matos, D. L., Laurenti, R., de Mello-Jorge, M. H. P., \& Cesar, C. C. (2010). Tendências e fatores associados aos óbitos por causas mal definidas em idosos: Nove anos de seguimento da coorte de Bambuí (Brasil). Cadernos de Saude Publica, 26(3), 514-522. https://doi.org/10.1590/S0102$311 \times 2010000300009$

Lima, M. S., Siqueira, H. F. F., Moura, A. R., Hora, E. C., Brito, H. L. de F., Marques, A. D., Brito, É. de A. C., Cipolotti, R., \& Lima, C. A. (2020). Temporal trend of cancer mortality in a Brazilian state with a medium Human Development Index (1980-2018). Scientific Reports, 10(1), 1-9. https://doi.org/10.1038/s41598-020-78381-4

Malta, M., Cardoso, L. O., Bastos, F. I., Magnanini, M. M. F., \& Silva, C. M. F. P. da. (2010). Iniciativa STROBE: subsídios para a comunicação de estudos observacionais. Revista de Saúde Pública, 44(3), 559-565. https://doi.org/10.1590/S0034-89102010000300021

Martins Junior, D. F., Costa, T. M., Lordelo, M. S., \& Martins Felzemburg, R. D. (2011). Tendência dos óbitos por causas mal definidas na região Nordeste do Brasil, 1979-2009. Revista Da Associação Médica Brasileira, 57(3), 338-346. https://doi.org/10.1590/S0104-42302011000300019

Martins Junior, D. F., Felzemburg, R. D. M., Dias, A. B., Costa, T. M., \& Santos, P. N. P. (2016). Trends in mortality from ill-defined causes among the elderly in Brazil, 1979-2013: ecological study. Sao Paulo Medical Journal, 134(5), 437-445. https://doi.org/10.1590/1516-3180.2016.0070010616

Muzy, J., Castanheira, D., \& Romero, D. (2021). Análise da qualidade da informação da mortalidade prematura por doenças crônicas não transmissíveis e sua utilização nos Objetivos de Desenvolvimento Sustentável. Cadernos Saúde Coletiva. https://doi.org/10.1590/1414-462x202199010456

ORGANIZAÇÃO MUNDIAL DE SAÚDE. (2014). CID-10/Tradução Centro Colaborador da OMS para a Família Classificações em Português. (Universidade de São Paulo (ed.); 10 rev. 5.).

Özdemir, R., Rao, C., Öcek, Z., \& Dinç Horasan, G. (2015). Reliable mortality statistics for Turkey: Are we there yet? BMC Public Health, 15(1), 1-12. https://doi.org/10.1186/s12889-015-1904-1

Paes, N. A. (2007). Quality of death statistics by unknown causes in Brazilian States. [Portuguese] $1 n$ Qualidade das estatisticas de obitos por causas desconhecidas dos Estados brasileiros. Revista De Saude Publica, 41(3), 436-445. http://www.scielo.br/pdf/rsp/v41n3/5665.pdf

Prestes, C., Costa, M. da C. N., Lima, R. da C., Barreto, F. R., \& Teixeira, M. da G. (2018). Tendência da mortalidade por causas mal definidas no estado do Tocantins e na sua capital Palmas, 1998-2014*. Epidemiologia e Serviços de Saúde, 27(3). https://doi.org/10.5123/S1679-49742018000300011

Red Interagencial de, \& Información para la Salud. (2009). Indicadores básicos para la salud en Brasil: conceptos y aplicaciones (p. 349). http://bvsms.saude.gov.br/bvs/publicacoes/indicadores_basicos_salud_brasil.pdf

Regional, E., As, P. as A., Regional, E., \& As, P. (2018). $29^{\text {a }}$ Conferência sanitária pan-americana $69^{\mathrm{a}}$ sessão do comitê regional da oms para as américas. agenda de saúde sustentável para as américas 2018-2030: Um Chamado à Ação Para a Saúde e o Bem-Estar Na Região, 1-60.

Rodrigues, N. C. P., Daumas, R. P., de Almeida, A. S., O'dwyer, G., Andrade, M. K. de N., Flynn, M. B., \& Lino, V. T. S. (2018). Risk factors for the illdefined causes of deatin the Brazilian states: A multilevel analysis. Ciencia e Saude Coletiva, 23(11), 3979-3988. https://doi.org/10.1590/1413812320182311.27182016

Santo, A. H. (2008). Causas mal definidas de morte e óbitos sem assistência. Revista Da Associação Médica Brasileira, 54(1), 23-28. https://doi.org/10.1590/S0104-42302008000100016

Santos, J. A. da S., \& Rodrigues, D. F. (2019). [Id 41292] Análise Comparativa Do Sistema De Informação De Mortalidade Entre Municípios De Uma Regional De Saúde Do Estado De Pernambuco. Revista Brasileira de Ciências Da Saúde, 23(3), 253-262. https://doi.org/10.22478/ufpb.2317$6032.2019 \mathrm{v} 23 \mathrm{n} 3.41292$

Travassos, C., \& Martins, M. (2004). Uma revisão sobre os conceitos de acesso e utilização de serviços de saúde. Cadernos de Saúde Pública, 20(suppl 2), S190-S198. https://doi.org/10.1590/S0102-311X2004000800014

Ylijoki-Sørensen, S., Sajantila, A., Lalu, K., Bøggild, H., Boldsen, J. L., \& Boel, L. W. T. (2014). Coding ill-defined and unknown cause of death is 13 times more frequent in Denmark than in Finland. Forensic Science International, 244, 289-294. https://doi.org/10.1016/j.forsciint.2014.09.016 